\title{
An assessment of the ship drag penalty arising from light calcareous tubeworm fouling.
}

\author{
J. P. Monty ${ }^{\mathrm{a}}$, E. Dogan ${ }^{\mathrm{b}}$, R. $\operatorname{Hanson}^{\mathrm{b}}$, A. J. Scardino ${ }^{\mathrm{c}}$, B. Ganapathisubramani ${ }^{\mathrm{b}}$, N. Hutchin \\ ${ }^{a}$ Department of Mechanical Engineering, \\ University of Melbourne, Parkville, VIC 3010 Australia; \\ ${ }^{b}$ Aerodynamics and Flight Mechanics Research Group, University of Southampton, UK; \\ ${ }^{c}$ Maritime Platforms Division, Defence Science and Technology Organisation, Melbourne, Victoria,
}

August 7, 2015

\begin{abstract}
A test coupon coated with light calcareous tubeworm fouling was scanned, scaled and reproduced for wind-tunnel testing to determine the equivalent sand grain roughness $k_{s}$. It was found that this surface had a $k_{s}=0.325 \mathrm{~mm}$, substantially less than previously reported values for light calcareous fouling. Any number of variations in surface topology could account for these different report values, such as sparseness, differences in species settlement etc. The experimental results were used to predict the drag on a fouled full scale ship. To achieve this, a modified method for predicting the total drag of a spatially developing turbulent boundary layer (TBL), such as that on the hull of a ship, is presented. The method numerically integrates the skin friction over the length of the boundary layer, assuming a widely accepted analytical form for the mean velocity profile of the TBL. The velocity profile contains the roughness (fouling) information, such that the prediction requires only an input of $k_{s}$, free-stream velocity (ship speed), kinematic viscosity and the length of the boundary layer (hull length). Using the equivalent sandgrain roughness height determined from experiments, a FFG-7 Oliver Perry class Frigate is predicted to experience a $23 \%$ increase in total resistance at cruise, if its hull is coated in light calcareous tubeworm fouling. A similarly fouled Very Large Crude Carrier would experience a $34 \%$ increase in total resistance at cruise.

turbulent boundary layer, skin friction drag, roughness, tubeworms
\end{abstract}

\section{Introduction}

For engineers and marine hydrodynamicists, a biofouled hull represents a surface roughness that can increase skin friction drag, leading to increases in powering requirements (or reductions in steaming speed). Such effects have significant implications to the efficiency, economy and emissions of ship transportation (see Lewthwaite et al. [1984], Townsin [2003], Schultz [2007], Schultz et al. [2011] and references, for an estimate of the hull fouling penalty).

A key step in assessing the hydrodynamic impact of a given biofouling on a maritime platform is the determination of the equivalent sand-grain roughness $\left(k_{s}\right)$ for the surface condition. Unlike

**Corresponding author. Email: montyjp@unimelb.edu.au 
other surface properties, such as root-mean-square roughness height, effective slope or max peakto-trough height, the equivalent sand-grain roughness is not a directly measurable length-scale of the surface. Rather, it is a measure of the influence of the roughness on the wall-bounded flow (and therefore can only be assessed by exposing the surface to a flow). The concept of an equivalent sand-grain roughness is an artifact of Nikuradse's Nikuradse [1932] pioneering measurements on turbulent pipe flows roughened with mono-disperse sand grains, and provides a convenient method of characterising the drag increment caused by a given surface and relating the behaviour of more complicated surface geometries back to Nikuradse's original measurements.

At present, $k_{s}$ is typically determined by exposing the rough surface to a flow and carefully measuring the friction drag coefficient $C_{f}$. This must be repeated across a range of conditions until $C_{f}$ (at a given $x$ location) becomes invariant with variations in flow velocity, at which point the flow/surface is referred to as being 'fully rough'. Experimentally, there are numerous procedures for achieving this. If a sample of the biofouling can be obtained (or replicated) the drag, and hence $k_{s}$ can be measured using tow-tank measurements, rotating disk experiments, or by measuring mean velocity profiles in the turbulent boundary layers formed over the roughness (see Schultz \& Myers [2003] for a comparison of these methods). For the latter technique, involving profile measurements, the boundary layers could be formed in an experimental water or wind-tunnel facility, or even in situ on the hull of a ship Lewthwaite et al. [1984]. The advantage of the in situ method is that the fouled surface is evaluated in its natural environment, and does not need to be transferred into the laboratory on either specially prepared coupons Walker et al. [2013], Schultz \& Swain [1999], or using replicated surface geometries Wu \& Christensen [2007]. Advantages of replicated geometries (recreated through casting, machining, rapid prototyping or combinations) are that it is not necessary to introduce fouling into sensitive experimental facilities and the surfaces can be scaled for testing at different conditions. However, the rigid replicated surfaces preclude the evaluation of soft fouling (which are believed to move under realistic flow conditions, altering the effective roughness Schultz \& Swain [2000], Walker et al. [2013, 2014]).

The ultimate goal for roughness research is to bypass this costly step by formulating functions that enable a direct calculation of the equivalent sandgrain roughness given some easily measured properties of the surface (such as root-mean-square roughness height, effective slope etc). The growing database of rough surface experiments has aided the formulation of certain empirical relationships along these lines (see Flack \& Schultz Flack \& Schultz [2010] for a comprehensive review). Though many of these predictive methods work reasonably well for the surfaces on which they were formulated (e.g. painted surfaces, antifouling coatings, cast or honed surfaces), none seem to be broadly applicable across the wide range of roughness geometries that can be encountered due to marine biofouling.

Eventually, Direct Numerical Simulations (DNS) may bypass the need for costly experimental determination of $k_{s}$. In recent years, there are increasing examples in the literature where DNS has been used to investigate realistic scanned rough surfaces Busse et al. [2013, 2015]. There are also examples where DNS or Large Eddy Simulation (LES) have been employed to compute the equivalent sandgrain roughness of particular surface topologies Yuan \& Piomelli [2014], Chan et al. [2015], Thakkar et al. [2015]. Though these studies are promising, the surfaces tested to date are all relatively homogeneous, with compact wall-parallel scales, and hence lend themselves well to efficient computations in limited numerical domains. This approach is embodied in the recently reported minimal channel method of Chung et al. Chung et al. [2015] which, using a severely truncated DNS domain, yields $k_{s}$ for small-scale homogeneous roughnesses at a fraction of the cost associated with full domain simulations. However, despite these advances, DNS of rough surfaces 
exhibiting large wall-parallel length scales, sparseness or heterogeneity (such as the biofouled surface investigated here) will likely remain prohibitively expensive for the foreseeable future.

Regardless of the technique used, once the equivalent sand-grain roughness has been established for a surface, it is possible to use this result to predict the full-scale behaviour in higher Reynolds number situations, using either the Moody chart for fully-developed pipe flow Moody [1944], Schockling et al. [2006], or developments for the zero-pressure-gradient flat plate turbulent boundary layer Prandtl \& Schlichting [1955], Granville [1958]. Hence, the influence of the roughness on the drag, powering requirements, fuel consumption etc. can be estimated. Such methods exploit the Momentum Integral Equation (conservation of linear momentum) and also an assumed collapse in the velocity defect profiles between the smooth and the rough wall turbulent boundary layers. The latter concept is often referred to as 'outer layer similarity' (after Townsend's Townsend [1956] original hypothesis) and has important implications to the understanding of the physics of roughwall turbulent boundary layers; it suggests a similar turbulent structure for the majority of the layer. For this reason, this topic has been the subject of lively debate (see for example Krogstadt \& Antonia [1999], Schultz \& Flack [2005], Flack et al. [2007], Wu \& Christensen [2007] and discussions within Nickels [2010]). However, the pertinent ramification of outer layer similarity here, is that it permits full-scale drag predictions (via the assumed self-similar velocity profiles - see $\S \&$ ).

There are numerous previous examples in the literature that attempt to quantify the drag penalty due to a biofouled surface. Lewthwaite et al. Lewthwaite et al. [1984] measured in situ boundary layer profiles on the hull of a small tender at various hull fouling conditions, calculating the skin friction coefficient. Unfortunately, detailed scans or data relating to the surface state for these experiments are unavailable, but there are diver descriptions of the hull fouling. Schultz Schultz [2007] used equivalent sandgrain roughness data for antifouling coatings in the fouled and un-fouled state (obtained from laboratory measurements Schultz [2004]) to estimate the change in resistance (and powering) for a Naval frigate. Leer-Andersen \& Larsson Leer-Andersen \& Larsson [2003] also attempted to detail the skin friction drag penalty due to realistic fouling by coating the inside of a split pipe with different anti-fouling coatings and barnacle growth, and measuring pressure drop through the system to infer the skin friction drag. Several other studies have specifically aimed to measure the baseline skin friction drag of antifouling and foul-release coatings in their un-fouled state (e.g. Candries et al. [2003], Schultz [2004]). Beyond this, numerous studies have attempted to characterise the skin friction drag due to biofilms grown on a test plate inserted into specially designed water tunnels Schultz \& Swain [1999], Walker et al. [2013] or towed-plates Schultz [2004].

The aim of this investigation is firstly to obtain an accurate measure for the equivalent sandgrain roughness height $\left(k_{s}\right)$ of a commonly encountered marine fouling. The measured $k_{s}$ is subsequently used to predict the performance of full-scale vessels operating under these hull conditions. The procedure and the structure of this paper is as follows:

1. Obtain a sample of a realistic calcareous fouling $(\S)$ and obtain an accurate surface scan of this fouled topology $(\S)$

2. Scale the surface for wind-tunnel testing and replicate the scaled surface in sufficient quantities to form the $4 \mathrm{~m}^{2}$ test surface area of the wind-tunnel facility (§).

3. Conduct accurate boundary layer measurements to determine the equivalent sand grain roughness $k_{s}(\S \&)$. 
4. Use this result to predict the drag penalty due to this fouling type in a full-scale system ( $§ \&$ ) .

\section{The test surface}

\section{Preparation of coupon}

An acrylic coupon measuring $300 \times 150 \times 3 \mathrm{~mm}$ was deployed at the Defence Science and Technology Organisation (DSTO) Marine Coatings exposure raft on Booth Pier, Williamstown, Victoria, Australia $\left(37^{\circ} 51^{\prime} 41.40^{\prime \prime} \mathrm{S}, 144^{\circ} 54^{\prime} 38.06^{\prime \prime} \mathrm{E}\right)$. The coupon was immersed with a north facing aspect at a depth of $1.5 \mathrm{~m}$ for 2 months over the Australian summer (December to February). The floating raft lies in Hobsons Bay, the northernmost part of Port Phillip Bay which is a large inland bay covering $2000 \mathrm{~km}^{2}$. The environmental conditions and early fouling succession of this site is documented by Watson et al. Watson et al. [2014] and longer term fouling assemblages by Choi et al. Choi et al. [2013]. After the exposure period the coupon was photographed and then air dried for 7 days prior to storing at $-18^{\circ} \mathrm{C}$ until the sample was required for scanning. The predominant fouling recorded on the coupons after the exposure period were serpulid tubeworms comprising Hydroides sp., Galeolaria sp. and Spirorbid sp. This type of light calcareous fouling is rated as FR 40 by Schultz Schultz [2007], Schultz et al. [2011]. Interspersed between the calcareous fouling was a combination of light slime and moderate weed fouling rated as between FR 10-20. There was also the emergence of hydroid fouling communities (Ectopleura sp.). This type of fouling growth is typical to that found on commercial fouling release coatings in similar environments and immersion periods [Scardino et al., 2009]. As the intention of this study was to record the effects of calcareous fouling, the soft fouling was allowed to dry out and hence will most likely have little bearing on the overall coupon roughness which is largely defined by the light calcareous tubeworm fouling. A photograph of the fouled coupon is overlaid on the scanned topology in figure 1(a).

\section{Surface scanning}

The surface topology of the coupon was scanned using a Keyence LK-031 laser triangulation sensor attached to a two-axis automated positioning system. The vertical $(z)$ resolution of the scan was $1 \mu \mathrm{m}$ and the horizontal ( $x$ and $y$ ) accuracy was $30 \mu \mathrm{m}$ with horizontal measurements taken on a grid spacing of $0.5 \mathrm{~mm}$. At locations of very steep gradients in the surface, the laser triangulation was unsuccessful resulting in data loss. Linear interpolation was used to fill in the data at such locations.

It is emphasised that, though recent research has suggested that flow induced movement of soft fouling can increase the equivalent roughness height Walker et al. [2013, 2014], for these experiments we are unable to test these phenomena, choosing instead to concentrate on a sparse rigid calcareous fouling based on a realistic (field-generated) tubeworm distribution. Figure 1 reveals that the scan has adequately resolved the underlying topology of the hard calcareous fouling. Despite the pronounced surface discoloration caused by the soft fibrous fouling, the elevation change owing to these regions is relatively small in comparison to the calcareous fouling. Table 1 collates key surface parameters calculated from the surface scan data, and also includes the PDF of the coupon topology. 


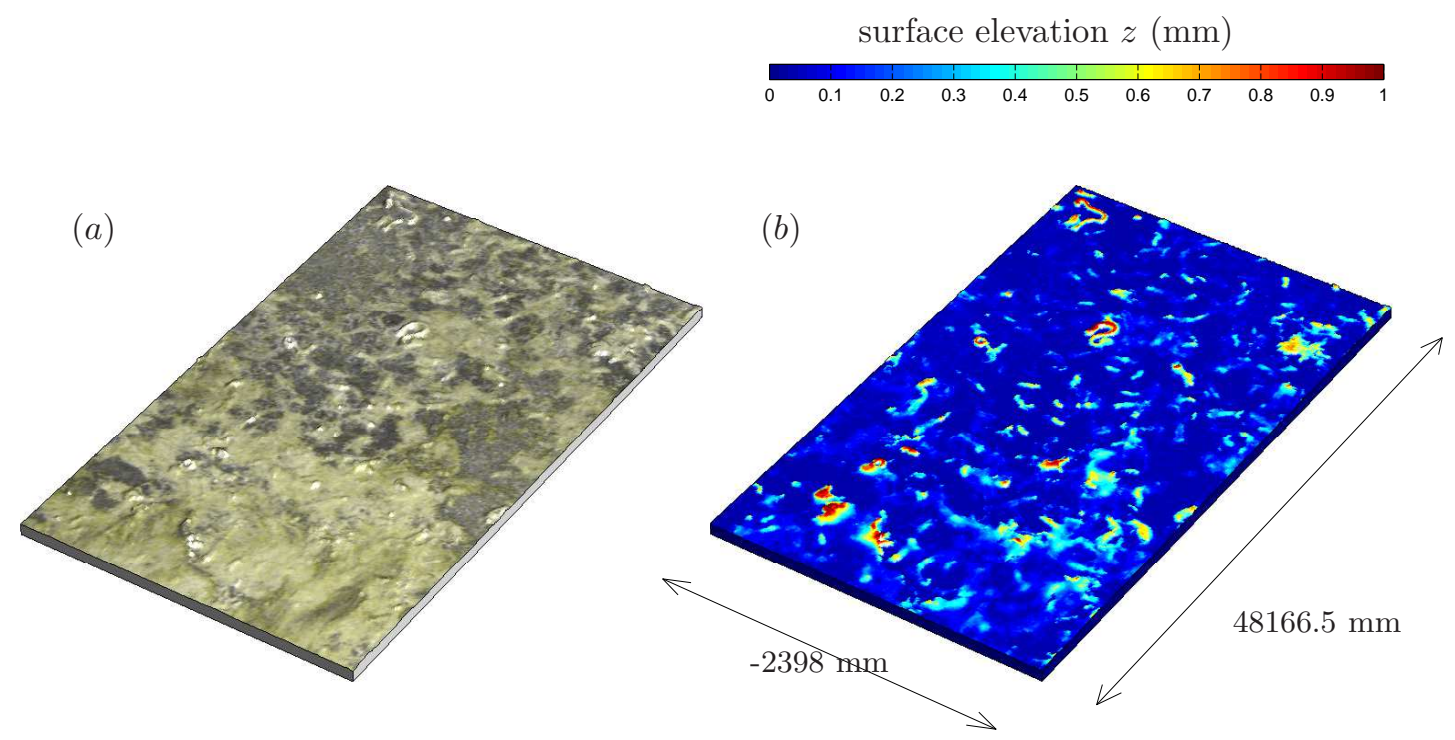

Figure 1: The tube-worm fouled surface. (a) Photograph of the fouled coupon overlaid on the scanned topology, depicting the true colour of the fouling; $(b)$ The laser surface scan, with the colour scale showing the elevation height of the surface topology.

Table 1: (left) Key surface parameters from the scanned surface data, where $z^{\prime}$ is the surface deviation about the mean height $\left(z^{\prime}=z-\bar{z}\right)$ (right) probability distribution function of the surface elevation.

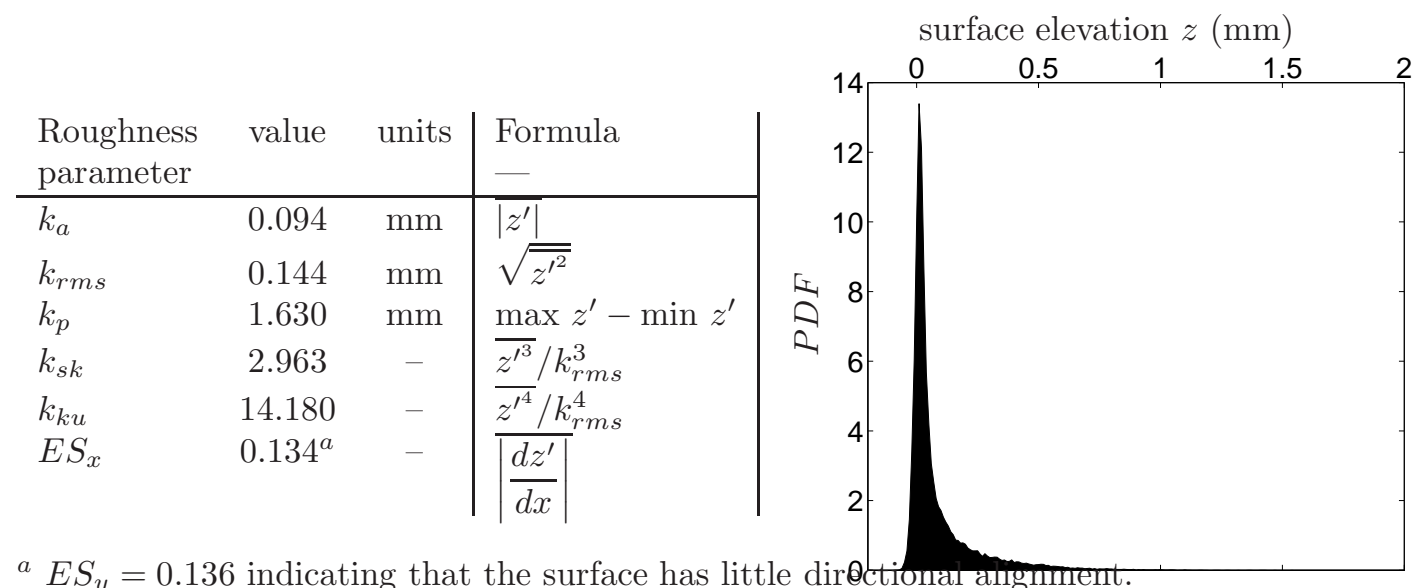




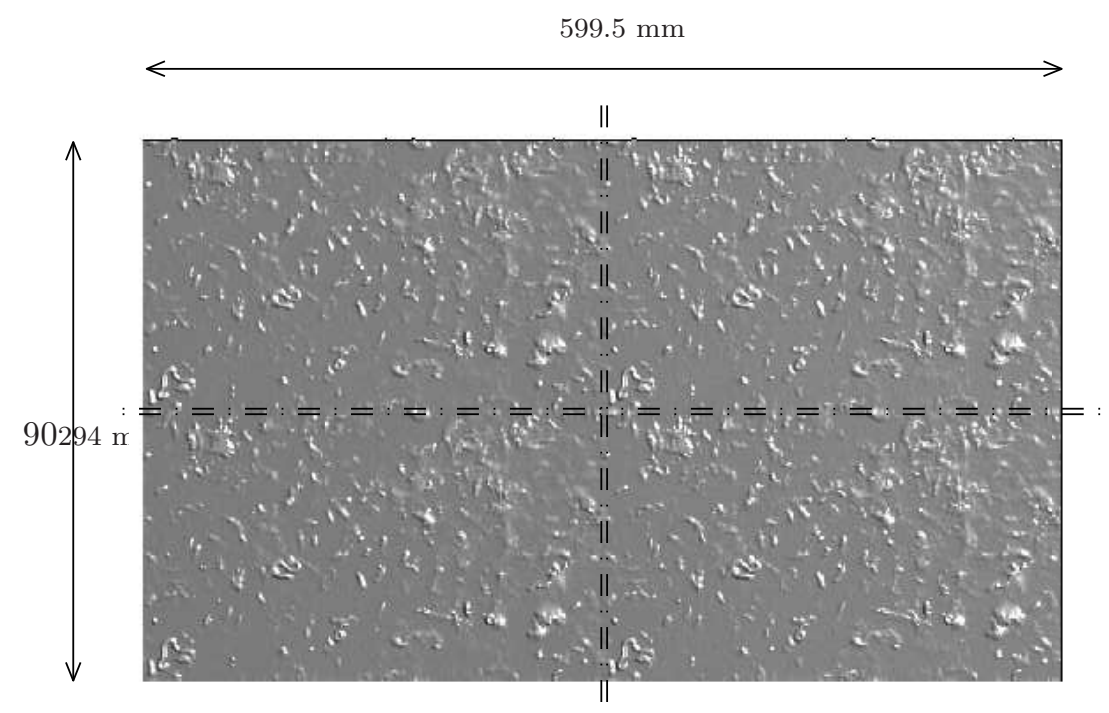

Figure 2: Periodic tile produced through blended interpolation in the region shown by dot-dashed lines. Surface geometry is scaled by factor 1.5 , such that repeating quadrant has dimensions $147 \times$ $249.75 \mathrm{~mm}$ and total tile size is $294 \times 499.5 \mathrm{~mm}$.

\section{Tile manufacture}

The surface was scaled by a factor 1.5 , based on a preliminary calculation of the requirements for fully rough conditions within the test facility, yielding a scan area of $249.75 \times 147 \mathrm{~mm}^{2}$. In order to produce the tiles, this pattern must be replicated in such a manner that the tile is periodic in $x$ and $y$. For these experiments, the tile is produced from four un-reflected quadrants as shown in figure 2. A blending region is established extending $\pm 1.5 \mathrm{~mm}$ about the edges, across which linear interpolation is applied to ensure a junction free of discontinuities. The edges of the tile are also replaced with these interpolated regions, to ensure a fully periodic tile.

To manufacture these surfaces, a similar manufacturing technique to that developed in Nugroho et al. [2012] was employed. A three-axis CNC machine was used to create a master tile in wax of the blended tubeworm surface depicted in figure 2. A mould of this tile was produced in platinum cured silicone rubber and used to cast multiple polyurethane reproductions of the original tile. The test surface comprises a total of 24 tiles.

\section{Test facility}

Experiments were performed in a suction-type wind tunnel at the University of Southampton. The tunnel has a settling section* with a honeycomb straightener and two screens, followed by a 7:1 contraction and a working section* of $4.5 \mathrm{~m}$ in length, with a $0.9 \mathrm{~m}$ wide and $0.6 \mathrm{~m}$ high 
cross-section*. The tunnel then has a diffuser section* and, finally, a fan. The 24 roughness tiles were placed on the bottom wall of the wind tunnel, covering the full width and a length of $4 \mathrm{~m}$. All measurements were carried out at a downstream location of $3.5 \mathrm{~m}$ (from the inlet of the test section*, which is also the start of the roughness).

Velocity profile measurements were carried out using hot-wire anemometry over a range of freestream velocities. A single Auspex A55P05 boundary layer probe was used. These probes had a sensing element of $5 \mu \mathrm{m}$ diameter tungsten wire with an exposed length of $1.05 \mathrm{~mm}$. The single probe had a length to diameter ratio of 210, which is in line with recommendations made in previous studies Ligrani \& Bradshaw [1987], Hutchins et al. [2009]. The hot-wire probes were operated using a constant temperature anemometer (CTA), Dantec Streamline Pro CTA, with an overheat ratio of 1.8. The data was low-pass filtered at $30 \mathrm{kHz}$ (which is well above the viscous scale frequency) and sampled with a 16-bit National Instruments USB-6212 A/D card at $80 \mathrm{kHz}$. In-situ static calibrations of the hot-wires were performed immediately before and after each experiment to quantify any drift of the hot-wires over the time of the experiment; in all experiments presented, hot-wire drift was negligible.

\section{Aerodynamic testing}

Wall-normal distributions of various statistics are shown in figure 3. The velocity defect, 3(a), and the turbulence intensity, 3(b), are used to determine the skin friction by assuming Townsend's outer layer similarity hypothesis Townsend [1976]. The hypothesis states that both the turbulence intensity and the velocity defect data scaled with the correct velocity scale, $U_{\tau}$, should be independent of roughness and Reynolds number in the outer region, i.e.,

$$
\begin{array}{r}
\overline{u^{2}}=\frac{\overline{u^{2}}}{U_{\tau}^{2}}=f\left(\frac{z}{\delta}\right) \\
U_{\infty}^{+}-U^{+}=\frac{U_{\infty}-U}{U_{\tau}}=g\left(\frac{z}{\delta}\right),
\end{array}
$$

Here $\overline{u^{2}}$ is the variance of the streamwise velocity fluctuations (turbulence intensity). The ' + ' superscript refers to viscous scaling of velocity (e.g. $U^{+}=U / U_{\tau}$ ) and wall-normal distance (e.g. $\left.z^{+}=z U_{\tau} / \nu\right)$. Note that these equations strictly only apply as $R e_{\tau} \rightarrow \infty$, however, previous studies have shown equation 1 holds for $z / \delta>0.15$ and equation 2 when $z^{+}>100$ [Schultz \& Flack, 2007, Flack et al., 2007, Monty et al., 2011] even at the Reynolds numbers of the current study. Moreover, the functions $f$ and $g$ should be the same for both the rough and smooth wall and hence there is a unique solution of $U_{\tau}$ for the rough wall data that can cause the two independent statistics ( $U$ and $\left.\overline{u^{2}}\right)$ to collapse on to the smooth wall data.

A simple procedure was used to simultaneously minimise the difference in velocity defect and turbulence intensity between the scaled smooth wall data and the rough wall data for a range of $U_{\tau}$. The $U_{\tau}$ corresponding to the minimum combined difference is the inferred rough-wall value. This is the same procedure used by Monty et al. [2011]. Figures 3(a) and (b) clearly demonstrate that it is possible to find a $U_{\tau}$ for each rough-wall profile that collapses the data onto the smooth wall profiles within experimental error, thus confirming Townsends similarity hypothesis (note that the procedure to find $U_{\tau}$ only minimises the difference between smooth and rough data, it does not guarantee simultaneous collapse of all scaled data across the Reynolds number range; this was also discussed in more detail in Monty et al. [2011]). Outer layer similarity is critical for the drag 

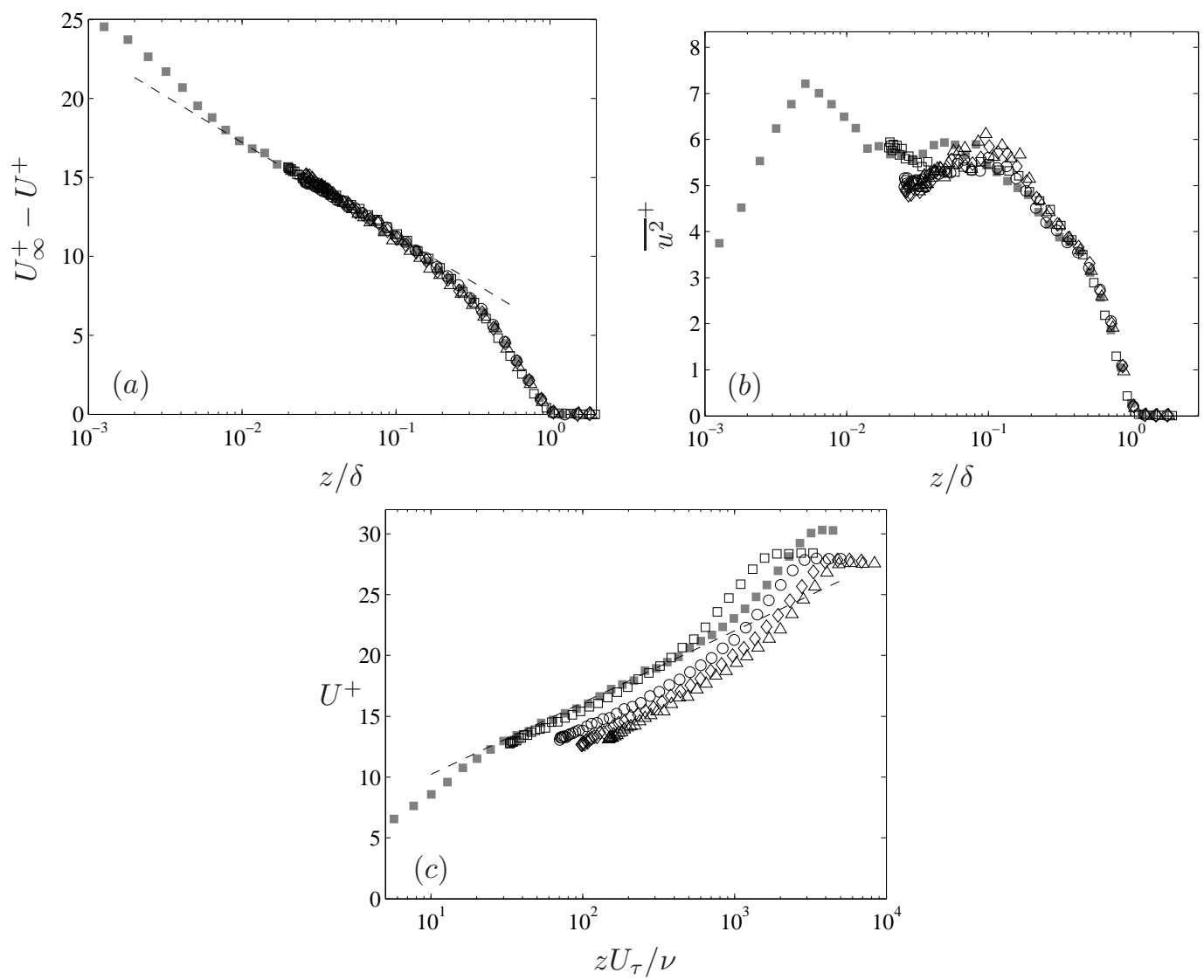

Figure 3: Wall-normal distributions of: (a) mean streamwise velocity defect; (b) streamwise turbulence intensity; (c) inner-scaled mean velocity. Solid grey squares are smooth wall data taken at $U_{\infty}=20 \mathrm{~m} / \mathrm{s}$ with $R e_{\tau}=3150$, open symbols are rough wall data with: , $U_{\infty}=10 \mathrm{~m} / \mathrm{s}$, $R e_{\tau}=1700 ; \circ, U_{\infty}=15 \mathrm{~m} / \mathrm{s}, R e_{\tau}=2800 ; \diamond, U_{\infty}=20 \mathrm{~m} / \mathrm{s}, R e_{\tau}=3800 ; \triangle, U_{\infty}=25 \mathrm{~m} / \mathrm{s}$, $R e_{\tau}=4600$.

prediction performed in the following section*s. With $U_{\tau}$ determined in this way, the inner-scaled velocity profiles are shown in figure $3(\mathrm{c})$. The velocity profiles display the well-known downward shift, $\Delta U^{+}$(relative to the smooth wall case), with increasing roughness effect.

For the purposes of this paper, we are only interested in how the downward shift in mean velocity, $\Delta U^{+}$varies with the equivalent sand-grain roughness height. That is, we need only a bulk statistic of the flow. Taking full velocity profiles at a given flow speed is a time-consuming task that produces only one value of $\Delta U^{+}$per experiment. So a novel procedure to acquire the required data based on a single point measurement was designed and is described below.

The hot-wire probe was calibrated and moved to a location of $z=21.575 \mathrm{~mm}$. Across the Reynolds number range studied, this location was known to be between $z / \delta=0.25-0.6$ from earlier velocity profile measurements. Thus the probe was always in the outer region. In this region, the turbulence intensity and velocity defect scaled with $U_{\tau}$ are Reynolds number and roughness 


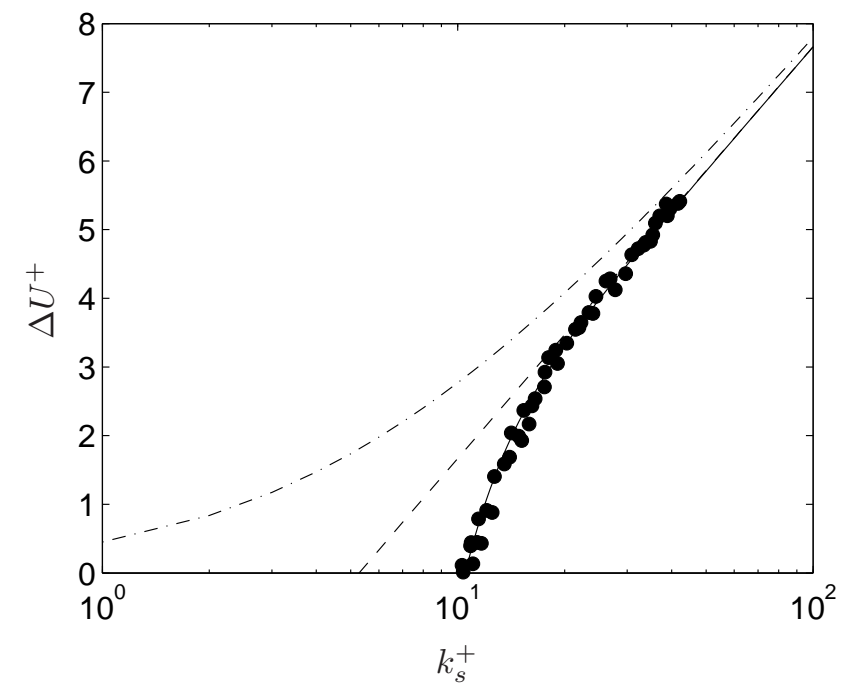

Figure 4: Velocity profile shift as function of roughness Reynolds number. Closed circles are from 3 runs where the wire was held at $z_{1}=21.575 \mathrm{~mm}$ and the free-stream velocity was varied from $9-36 \mathrm{~m} / \mathrm{s}$. The dashed line is equation 3; the dot-dashed line is from Colebrook \& White [1937]; the solid line is a curve-fit to the data (equation 14).

height independent according to Townsend, such that equations $1 \& 2$ hold simultaneously.

From our single point measurement, $U$ and $\overline{u^{2}}$ are known and the reference pitot probe in the wind-tunnel provides $U_{\infty}$. Since there are only two unknown quantities in equations $1 \& 2$, it is possible to determine $U_{\tau}$ without knowledge of $\delta$. However, for improved accuracy we used a curve-fit of earlier velocity profile measurements over the rough surface to determine $\delta$ as a function of $R e_{x}=U_{\infty} x / \nu$. Once $U_{\tau}$ was calculated, $\Delta U^{+}$was determined by assuming a universal function for the outer region of the velocity defect profile, $g(z / \delta)(2)$. Given $U_{\tau}$, the common practice of determining $k_{s}$ by forcing the highest Reynolds number measurement to obey the fully rough asymptote was followed,

$$
\Delta U^{+}=\frac{1}{\kappa} \ln k_{s}^{+}+A-B
$$

where $\kappa$ and $A$ are the standard log law constants (in this paper we will use $\kappa=0.384$ and $A=4.17$ ) and $B$ is typically taken to be 8.5 (following Nikuradse Nikuradse [1932]). This results in $k_{s}=325$ $\mu \mathrm{m}$ for this surface, which is very similar to that found for heavy slime coatings $\left(k_{s}=0.3 \mathrm{~mm}\right)$, and substantially less than that specified for small calcareous fouling or weed $\left(k_{s}=1 \mathrm{~mm}\right)$, Schultz $[2004,2007])$. The difference between the latter and our results is most likely due to differences in surface topology, such as sparseness, roughness height etc.

Many of these single-location measurements were conducted over the tunnel velocity range of $9-36 \mathrm{~ms}^{-1}$ and the data are shown in figure 4 . The behaviour of $\Delta U^{+}$differs markedly from the Colebrook-type roughness (dashed line). At the lowest Reynolds numbers tested, where $k_{s}^{+} \approx 10$ and $U_{\infty} \approx 10 \mathrm{~ms}^{-1}$, there is almost no roughness effect on the mean velocity profile; this can also be seen in figure $3 c$, where the velocity profile at $U_{\infty}=10 \mathrm{~ms}^{-1}$ is barely shifted downward in the log region, relative to the smooth case. Ligrani \& Moffat Ligrani \& Moffat [1986] also showed 
a surface that remained dynamically smooth until $k_{s}^{+} \approx 15$. As $k_{s}^{+}$increases, $\Delta U^{+}$rises sharply toward equation 3 . Judging by the collapse of the data onto equation 3 for $k_{s}^{+} \approx 20$ and above, it is concluded that the turbulent flow has become fully rough at $U_{\infty}=19 \mathrm{~ms}^{-1}$ (corresponding to $k_{s}^{+}=20.5$ ). Surfaces having a similarly low threshold of $k_{s}^{+}$for fully rough conditions have been reported by Schultz \& Flack [2007]. Assuming the fully rough condition has been met, we can use the determined value of $k_{s}$ for the sparse tubeworm surface to estimate the drag on a full-scale ship having a similarly fouled hull-state.

\section{Integral Boundary Layer Evolution}

If we assume a functional form for the mean velocity profile, it is possible to use the mean momentum integral equation to calculate certain aspects of the downstream boundary layer evolution on a zero-pressure-gradient (ZPG) flat plate. The process described here is similar to that described previously by Prandtl \& Schlichting Prandtl \& Schlichting [1955] and Granville Granville [1958], except in this case no effort is made to solve the integral equations algebraically, and instead we seek a numerical solution as described in ITTC [2008] (though without the iterative approach). The advantage of this approach, is that it is relatively easy to incorporate different functional forms for the mean profile, the procedure can cope with varying roughness heights along the flat plate, and we are not forced into approximations in order to simplify the algebra.

We start from the definition for the momentum thickness $\theta$ for a turbulent boundary layer,

$$
\theta=\int_{0}^{\delta} \frac{U}{U_{\infty}}\left(1-\frac{U}{U_{\infty}}\right) d z=\frac{\nu}{U_{\tau}} \int_{0}^{\delta^{+}}\left(\frac{U^{+}}{S}-\frac{U^{+^{2}}}{S^{2}}\right) d z^{+}
$$

where $U$ is the mean velocity profile (which is a function of $z$ ) and $S\left(=U_{\infty} / U_{\tau}\right)$ is the viscous scaled mean velocity at the edge of the boundary layer. The above expression can be rewritten in terms of the Reynolds number based on momentum thickness,

$$
R e_{\theta}=\frac{U_{\infty} \theta}{\nu}=\int_{0}^{\delta^{+}}\left(U^{+}-\frac{U^{+^{2}}}{S}\right) d z^{+} .
$$

It is straightforward to evaluate (5) if we assume a functional form for the viscous-scaled mean velocity profile $\left(U_{f}^{+}\right)$. There are plenty of functional forms for $U^{+}$, most of which consist of an inner/buffer region profile (I, e.g Spalding Spalding [1961], Van Driest Driest [1956], Reichardt Reichardt [1951] etc), a logarithmic function $(L)$ and a wake profile ( $W$, e.g. Coles Coles [1956], Jones et al. Jones et al. [2001]).

Ignoring for the time-being the precise form of the assumed velocity profile, if we let,

$$
G_{1}\left(\delta^{+}, \Pi\right)=\int_{0}^{\delta^{+}} U_{f}^{+} d z^{+}, \quad G_{2}\left(\delta^{+}, \Pi\right)=\int_{0}^{\delta^{+}} U_{f}^{+^{2}} d z^{+}
$$

we have,

$$
\operatorname{Re}_{\theta}=\left[G_{1}\left(\delta^{+}, \Pi\right)-\frac{G_{2}\left(\delta^{+}, \Pi\right)}{S\left(\delta^{+}, \Pi\right)}\right]
$$




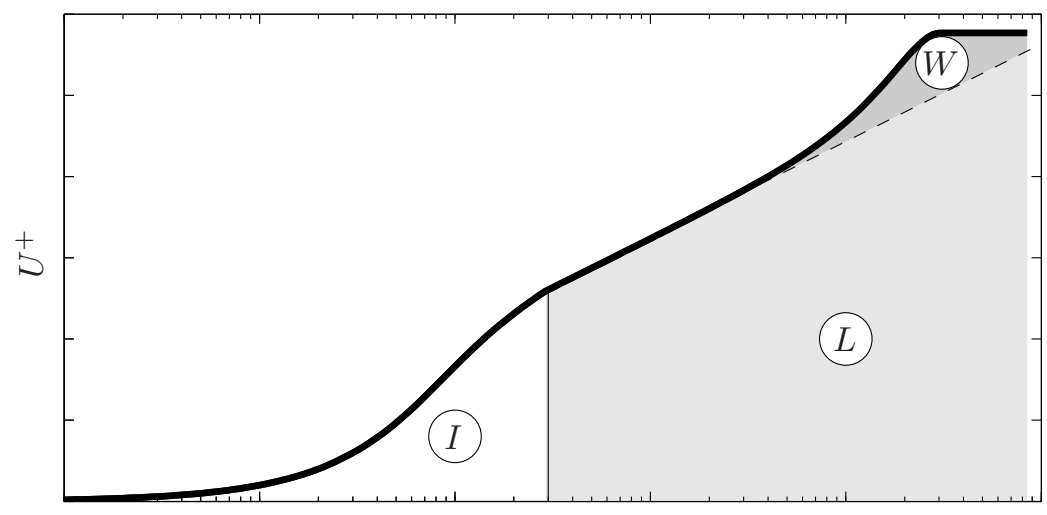

$$
\underbrace{0<z^{+}<z_{1}}_{U_{f}^{+}=I\left(z^{+}\right)} \underbrace{z_{1}<z^{+}<\delta^{+}}_{U_{f}^{+}=L\left(z^{+}\right)+W\left(z^{+}, \delta^{+}, \Pi\right)}
$$

Figure 5: Assumed viscous-scaled mean velocity profile for a smooth surface

So if we choose a $\delta^{+}$, we can use equations (6) and (7) to calculate the corresponding $R e_{\theta}$. The chosen $\delta^{+}$also yields a value for $S\left(=U_{\infty} / U_{\tau}\right)$, which is merely $U^{+}$evaluated at $z^{+}=\delta^{+}$, and hence (like $G_{1}$ and $G_{2}$ ) also a function of $\delta^{+}$and $\Pi$ only. If we assume the wake function of Jones et al. Jones et al. [2001] we can write,

$$
S=\frac{1}{\kappa} \log \delta^{+}+A-\Delta U^{+}-\frac{1}{3 \kappa}+\frac{2 \Pi}{\kappa},
$$

where the roughness function $\Delta U^{+}=0$ for a smooth surface. This in turn yields the local skin friction coefficient

$$
C_{f}=\frac{\tau_{w}}{\frac{1}{2} \rho U_{\infty}^{2}}=\frac{2}{S^{2}}
$$

So from our chosen range of $\delta^{+}$, we now know $\operatorname{Re}_{\theta}, C_{f}$, and $S$. For a zero-pressure-gradient flat plate turbulent boundary layer we also know (from the mean momentum integral equation) that,

$$
\frac{d \theta}{d x}=\frac{d R e_{\theta}}{d R e_{x}}=\frac{C_{f}}{2}
$$

Thus we can calculate the $x$-location where we expect the TBL to have the calculated bulk properties $\left(C_{f}, \operatorname{Re}_{\theta}, S\right)$, that is, we can calculate $R e_{x}$ from

$$
R e_{x}=\int \frac{2}{C_{f}} d R e_{\theta}
$$

which is evaluated numerically. The result for $R e_{x}$ enables the average skin friction coefficient $\overline{C_{f}}$ to be calculated, which is defined as,

$$
\overline{C_{f}}=\frac{1}{x} \int_{0}^{x} C_{f} d x^{\prime}=\frac{1}{R e_{x}} \int_{0}^{R e_{x}} C_{f} d R e_{x^{\prime}}
$$


where $x^{\prime}$ is just an intermediate variable coinciding with the $x$-coordinate. By integrating equation (10) and combining with equation (12) we get,

$$
\overline{C_{f}}=\frac{2 R e_{\theta}}{R e_{x}}
$$

A Matlab script demonstrating this calculation is included as Appendix

\section{Smooth Wall}

Figure 6 presents $\overline{C_{f}}$ against Reynolds number calculated using the method described above. The analysis uses the log-law constants $\kappa=0.384, A=4.17$ (given by Nagib et al. [2007]), the inner profile given by Reichardt Reichardt [1951], and the wake profile given by Jones et al. [2001]. A constant value of the wake strength parameter $\Pi=0.64$ was assumed, based on the recently observed behaviour in high Reynolds number ZPG TBLs Kulandaivelu [2012]. Also shown in figure 6 , are curves for scenarios where the inner region is ignored entirely (assumed logarithmic profile to the wall, shown by the dot-dashed line). The procedure outlined above requires a starting guess for $C_{f}$ at the initial value of $\delta^{+}$. The dashed curve shows a starting guess which is obviously too low (by approximately two orders of magnitude, $C_{f}=0.0003$ ). The black filled symbol shows a typical ship Reynolds number (FFG-7, Schultz [2007]). At these Reynolds numbers (order $10^{9}$ ), the predicted value is insensitive to the inclusion of the buffer region profile, or the starting guess (due to the parabolic nature of the equation system ITTC [2008]). Overall variation at this Reynolds number is less than $0.1 \%$ irrespective of starting guess or the inclusion of an inner profile. The largest sensitivity is to the value of $\Pi$. The dotted line in figure 6 shows a case with $\Pi=0.7$. Even with this variation in wake strength, at typical ship Reynolds numbers the variation in $\overline{C_{f}}$ is only $1 \%$, and therefore of negligible consequence to the primary conclusions of this work.

\section{Rough Wall}

The modelled mean velocity profile for the rough wall case incorporates a downward shift due to the roughness function $\Delta U^{+}$(see figure 7). It was observed above that the inner region makes little contribution to $\overline{C_{f}}$ (particularly at application Reynolds numbers); therefore, the logarithmic

region of the modelled velocity profile is extended to $z_{2}=e^{\kappa\left(\Delta U^{+}-A\right)}$, beyond which $u_{f}^{+}=0$ (for $\left.z<z_{2}\right)$.

From the wind tunnel experiments performed over the replicated tubeworm surface we have found that the following relationship describes the behaviour of the roughness function with $k_{s}^{+}$,

$$
\Delta U^{+}=\frac{1}{\kappa} \log \left(k_{s}^{+}\right)+A-B-\left(\frac{C}{k_{s}^{+}}\right)^{D}
$$

where $C$ and $D$ are determined from a best fit to the experimental data (12.3 and 3.7 respectively). Equation 14 has the correct asymptotic fully rough behaviour at large $k_{s}^{+}$. The equivalent sandgrain roughness for the tubeworm roughness has been determined from the experiments to be $k_{s}=325$ $\mu \mathrm{m}$. This value is assumed to be invariant with $x$ (and $R e_{x}$ ), equating to a homogeneous coating of the tubeworm roughness over the full surface area of the hull. However, the roughness Reynolds number $k_{s}^{+}$(and hence $\Delta U^{+}$) will vary with $x$ (and $R e_{x}$ ) reflecting the variation in local skin friction coefficient along the length of the hull. 


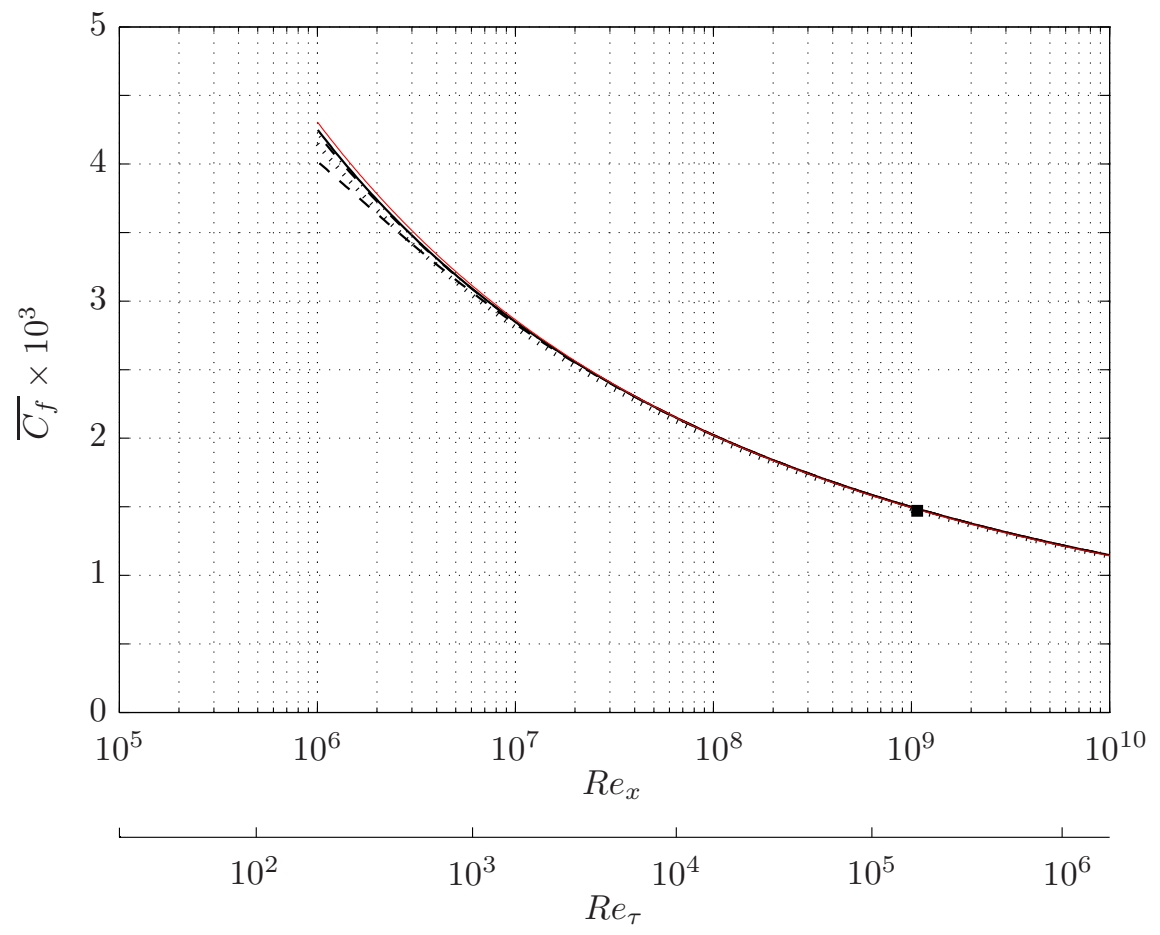

Figure 6: The average skin friction coefficient $\overline{C_{f}}$ against Reynolds number (both $R e_{x}$ and $R e_{\tau}(=$ $\left.\delta^{+}\right)$) for the evolved profile $(-)$full profile $(-\cdot)$ no inner region $(\cdots)$ altered wake strength $\Pi=0.70$ $(---)$ starting guess that is $50 \%$ too low (-) Schoenherr 1932 Schoenherr [1932], using the modified constant 0.2385 as suggested by Nagib et al. [2007] for the values of log law constants ( $\kappa$ and $A$ ) used here. The filled square symbol shows a typical ship Reynolds number (the FFG-7 frigate cruising at $7.7 \mathrm{~ms}^{-1}$ as analysed by Schultz Schultz [2007]).

The rough wall predictions involve a simple modification to the evolution procedure outlined in $\S$ and Appendix . Prior to evaluating $C_{f}$ or $\operatorname{Re}_{\theta}$ (from equations 7, $8 \&$ 9), the local equivalent sandgrain roughness Reynolds number,

$$
k_{s}^{+}=\frac{k_{s} U_{\infty}}{\nu} \sqrt{\frac{C_{f}}{2}}
$$

is evaluated (using the previous value of $C_{f}$ ). Note that in order to evaluate the effect of the roughness we must also input the ship's operating conditions $U_{\infty}$ and $\nu$. Equation (14) then provides the roughness function $\Delta U^{+}$, which when subtracted from the mean velocity profile (as shown in figure 7 ), enables $C_{f}$, and $R e_{\theta}$ (and hence $R e_{x}$ and $\overline{C_{f}}$ ) to be evaluated over the rough surface. The modifications to the similarity procedure required for rough-wall flow are outlined by the grey coloured text in the MATLAB script included in Appendix

Results from the rough wall evolution are shown in figure 8 for a range of unit Reynolds numbers. Lines of constant length are also shown in grey. The range of unit Reynolds numbers and lengths are 


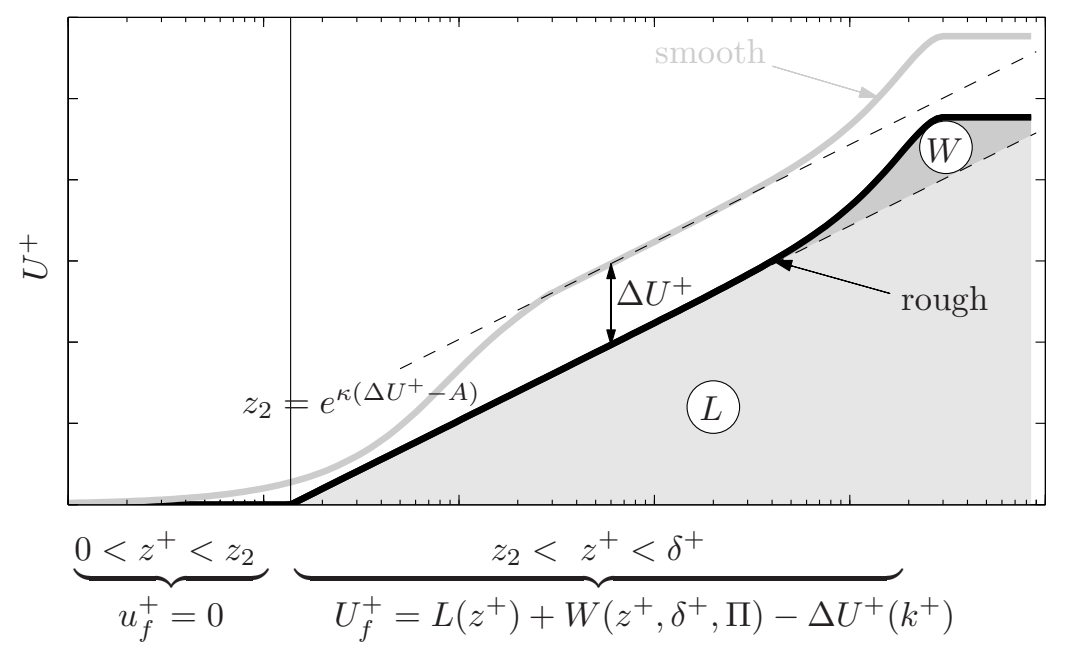

Figure 7: Assumed mean velocity profile for a rough surface

chosen to cover the approximate parameter space of most maritime applications. In the following section*s we consider the ramifications of these rough wall results to a few typical case studies.

\section{Case Studies}

Having produced figure 8 for the tubeworm fouling, we can now attempt to estimate the drag penalties on full-scale vessels. These predictions are somewhat simplified, based on the limited data available for these vessel types. However, they can in general give a feel for the penalty associated with this fouling condition. An operator who believes they have a fouling of this nature (with a PDF that closely conforms to that given in figure 1), should be able to use figure 8 , and the method outlined below, to produce an assessment of the likely drag penalty, and economic ramifications, enabling more informed operational decisions (i.e. on the scheduling of hull cleaning etc).

\section{FFG-7 Oliver Hazard Perry class Frigate}

\begin{tabular}{|c|c|c|c|c|c|c|c|c|c|}
\hline $\begin{array}{c}\text { Length } \\
(\mathrm{m})\end{array}$ & $\begin{array}{c}\nu \\
\left(\mathrm{m}^{2} \mathrm{~s}^{-1}\right)\end{array}$ & $C_{A}$ & $\begin{array}{c}U \\
\left(\mathrm{~ms}^{-1}\right.\end{array}$ & & $F r$ & $R e$ & $\overline{C_{f}} / C_{R}$ & $\% \Delta \overline{C_{f}}$ & $\% \Delta R_{T}$ \\
\hline \multirow{2}{*}{124} & \multirow{2}{*}{$8.97 \times 10^{-7}$} & \multirow{2}{*}{0.0004} & cruising & 7.7 & 0.22 & $1.06 \times 10^{9}$ & $\sim 0.7$ & $46 \%$ & $23 \%$ \\
\hline & & & full-speed & 15.4 & 0.44 & $2.13 \times 10^{9}$ & $\sim 3.3$ & $59 \%$ & $13 \%$ \\
\hline
\end{tabular}

Table 2: Tabulated data on FFG-7 Oliver Perry class Frigate taken from Schultz Schultz [2007]. Data in shaded columns are calculated for the tubeworm fouling.

We here use figure 8 to predict the change in total resistance and power requirements for the 


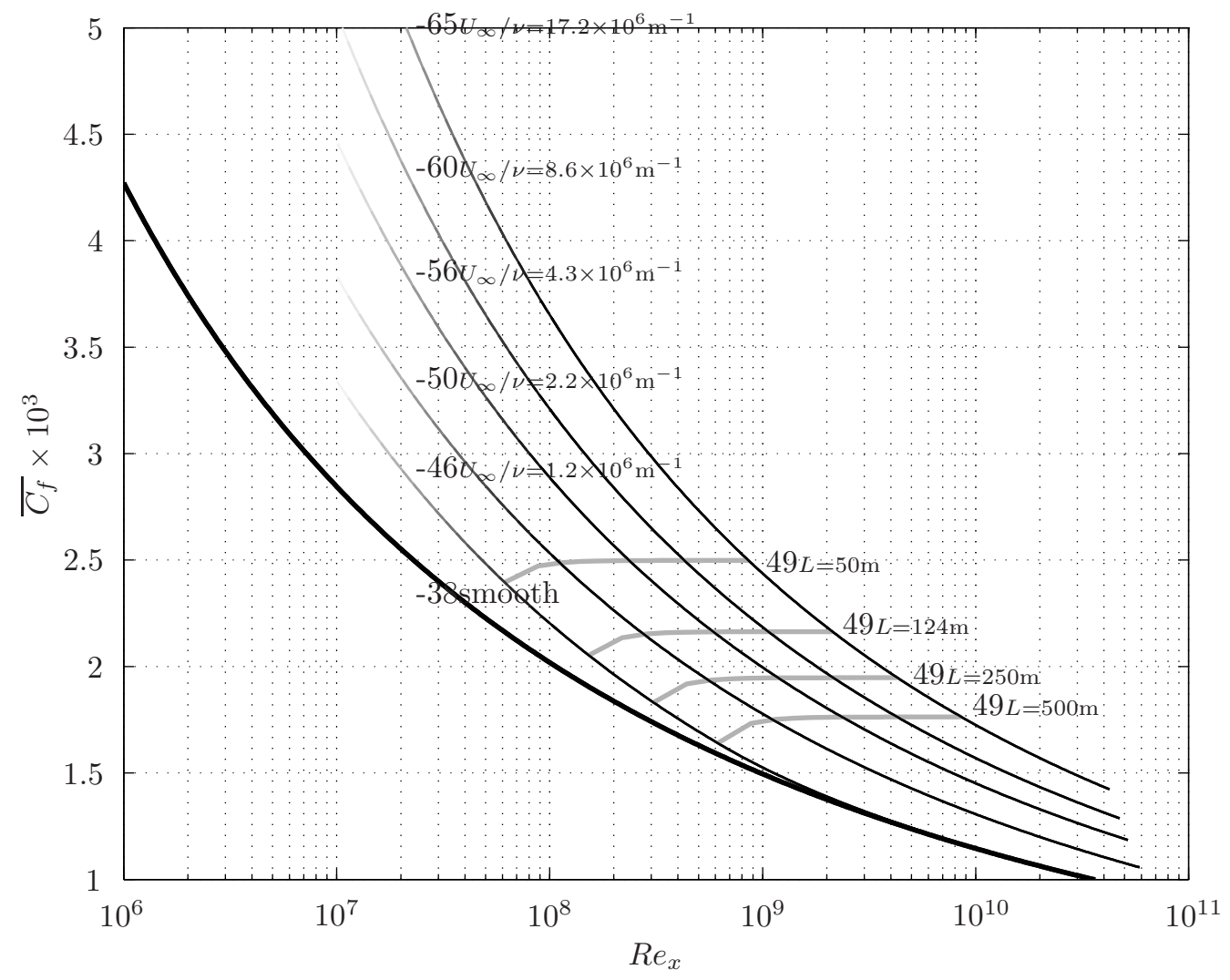

Figure 8: Average skin friction coefficient $\overline{C_{f}}$ against Reynolds number $R e_{x}$ for the (thick line) smooth surface and (thin lines) the tubeworm surface with $k_{s}=0.325 \mathrm{~mm}$. Curves are shown for a range unit Reynolds numbers $\left(U_{\infty} / \nu\right)$. Gray curves show contours of constant length.

FFG-7 frigate analysed by Schultz Schultz [2007]. Table 2 collates the particulars provided for this ship for both the cruising and full-speed operation. The two right-hand most columns (shaded) show calculations based on the current tubeworm roughness. The percentage change in average skin friction coefficient $\% \Delta \overline{C_{f}}$, is defined as,

$$
\% \Delta \overline{C_{f}}=100 \times\left.\frac{\Delta \overline{C_{f}}}{\overline{C_{f_{s}}}}\right|_{R e_{L}}
$$

where $C_{F_{s}}$ is the smooth wall friction coefficient at the ship $R e_{x}$ and $\Delta C_{F}$ is the difference between the rough and smooth (see figure 9). The percentage change in total resistance $\Delta R_{T}$ is given by,

$$
\% \Delta R_{T}=\frac{\Delta \overline{C_{f}}}{\overline{C_{f_{s}}}\left(1+\frac{C_{R}}{\overline{C_{f}}}\right)+C_{A}}
$$


where $\frac{C_{R}}{\overline{C_{f}}}$ is the ratio of residuary resistance to friction resistance (given as a function of Froude number $F r$ in Schultz [2007]) and $C_{A}$ is the correlation allowance (given as 0.0004 Schultz [2007]).

The results in table 2 demonstrate that the tubeworm fouling will cause an increase in total drag (compared to the smooth hull condition) of $23 \%$ and $13 \%$ for the cruise and full-speed conditions respectively. It should be noted that the increase in skin friction drag is much greater for the fullspeed case, however the corresponding increase in Froude number results in a larger contribution by the residuary resistance (due to wave-making resistance, which is assumed not to be a function of surface roughness) and hence the percentage increase in total drag is reduced. These numbers are very similar to those published by Schultz Schultz [2007] for the heavy slime case (which is not surprising, since the $k_{s}$ that we find for the tubeworms is very similar to that reported for the heavy slime Schultz [2007]). The percentage increases in required shaft power to maintain the same velocity with the fouled hull condition are the same as $\Delta R_{T}$, while the percentage reductions in speed at the same shaft power can be approximated by $\sqrt{\% \Delta R_{T}}$ Schultz [2007]. One can gain an indication of the potentially large economic impact of tubeworm fouling to the US fleet by referring to the heavy slime case in Schultz et al. [2011].

This analysis is based on an assumed kinematic viscosity of $8.97 \times 10^{-7}$, which is listed in ITTC [2011] as corresponding to a sea temperature of approximately $27^{\circ} \mathrm{C}$ (close to the tropics). At higher latitudes, the kinematic viscosity can be larger (by a factor of almost two), in which locations the percentage increments to total drag in cruise and full-speed operation are reduced to $18 \%$ and $10 \%$ respectively (although the magnitude of the total $C_{f}$ remains the same for both temperatures for the rough wall case).

\section{Very large crude carrier}

\begin{tabular}{|c|c|c|c|c|c|c|c|c|c|}
\hline $\begin{array}{l}\text { Length } \\
(\mathrm{m})\end{array}$ & $\begin{array}{c}\nu \\
\left(\mathrm{m}^{2} \mathrm{~s}^{-1}\right)\end{array}$ & $C_{A}$ & $\begin{array}{c}U \\
\left(\mathrm{~ms}^{-1}\right.\end{array}$ & & $F r$ & $R e$ & $\overline{C_{f}} / C_{R}$ & $\% \Delta \overline{C_{f}}$ & $\% \Delta R_{T}$ \\
\hline 320.0 & $8.97 \times 10^{-7}$ & 0.00024 & cruising & 8.7 & 0.15 & $3.10 \times 10^{9}$ & $\sim 0.08$ & $44 \%$ & $34 \%$ \\
\hline
\end{tabular}

Table 3: Approximate data for a VLCC taken from Min \& Kang [2012], ABS [2013]

Table 3 shows data for a very large crude carrier (VLCC). In this instance it is clear that the tubeworm fouling produces a comparable percentage increase in averaged frictional resistance $\Delta \overline{C_{f}}$ to that of the FFG-7 frigate. However, the vast majority of resistance for a VLCC is comprised of frictional resistance $(>90 \%)$, and hence the VLCC experiences much larger percentage increases in total resistance (and hence shaft power requirements) than the FFG-7 under the same hull roughness condition. When one considers that these ships can consume upwards of 100 tonnes of fuel per 24 hours Bendall [2010], with typical annual usage in excess of 280 days per annum Psaraftis \& Kontovas [2009], this 34\% drag penalty represents a large economic impact.

\section{Conclusions}

A method is outlined, whereby a realistic fouled surface is scanned, scaled and replicated to form the test surface for laboratory wind-tunnel experiments. Detailed boundary layer measurements, made using hot-wire anemometry, enable the equivalent sandgrain roughness height of the fouled 
surface to be accurately determined. The detailed boundary layer experiments also showed that outer layer similarity is preserved over the rough surface. This permits the subsequent use of the estimate for $k_{s}$ in a similarity law scaling procedure to produce a Moody-type diagram for a flat plate zero pressure gradient boundary layer developing over this particular fouled surface.

The tubeworm surface itself is interesting from a fundamental point of view, representing a surface roughness with an extreme sparseness that has rarely been studied. The variation of the roughness function with roughness Reynolds number is unusual for this surface, with little roughness effect up to $k_{s}^{+}=10$, beyond which the roughness function kicks up rapidly, seeming to become fully rough by $k_{s}^{+} \approx 20$ (very different to Colebrook Colebrook \& White [1937] or Nikuradse Nikuradse [1932] type roughness, but similar to Schultz \& Flack [2007]). The equivalent sandgrain roughness height for this surface is found to be $325 \mu \mathrm{m}$. This is approximately 5 times smaller than the maximum roughness element height. The equivalent sandgrain roughness found for this surface is also substantially smaller than the values reported for small calcareous fouling or weed $\left(k_{s}=1\right.$ $\mathrm{mm}$ ) by Schultz Schultz [2004, 2007]. This difference illustrates the danger of reducing complex biofouled topologies down to simple non-statistical descriptions. To maximise utility in application, any listed $k_{s}$ values from such studies should be accompanied by photographs, surface scans, and detailed surface parameters (such as those given in $\S 2$ ), to enable operators to judge which surface studied in the literature best matches their operating condition.

In cruise conditions, it is estimated that this relatively minor fouling condition will cause up to $23 \%$ increase in total resistance (and hence required shaft power) for a $124 \mathrm{~m}$ long frigate type geometry, and upwards of $34 \%$ increases for a very large crude carrier. This work has potential utility for ship operators, where hull fouling is encountered with similar surface properties (hull fouling that visually conforms to that represented in figure $1 a$ or with a measured PDF that conforms to that given in figure $1 b$ ). The techniques outlined in this paper, and the moody chart produced in figure 8 enable an assessment of the likely drag penalty, and economic ramifications arising from this fouling. This information could also enable more informed decisions regarding operations (scheduling of hull cleaning etc).

Further, it is hoped that this paper demonstrates a complete, yet relatively simple method, by which a common fouling type of interest can be studied in detail, to produce reliable predictions of drag penalties at full scale. 


\section{Example MATLAB script to demonstrate the similarity tech- nique}

The script below demonstrates the application of the integral similarity analysis for a smooth surface $\left(\Delta U^{+}=0\right)$ as detailed in $\S \& \S$. The additional lines of code shown in gray, demonstrate the modifications required for a rough wall of constant $k_{s}(\S)$.

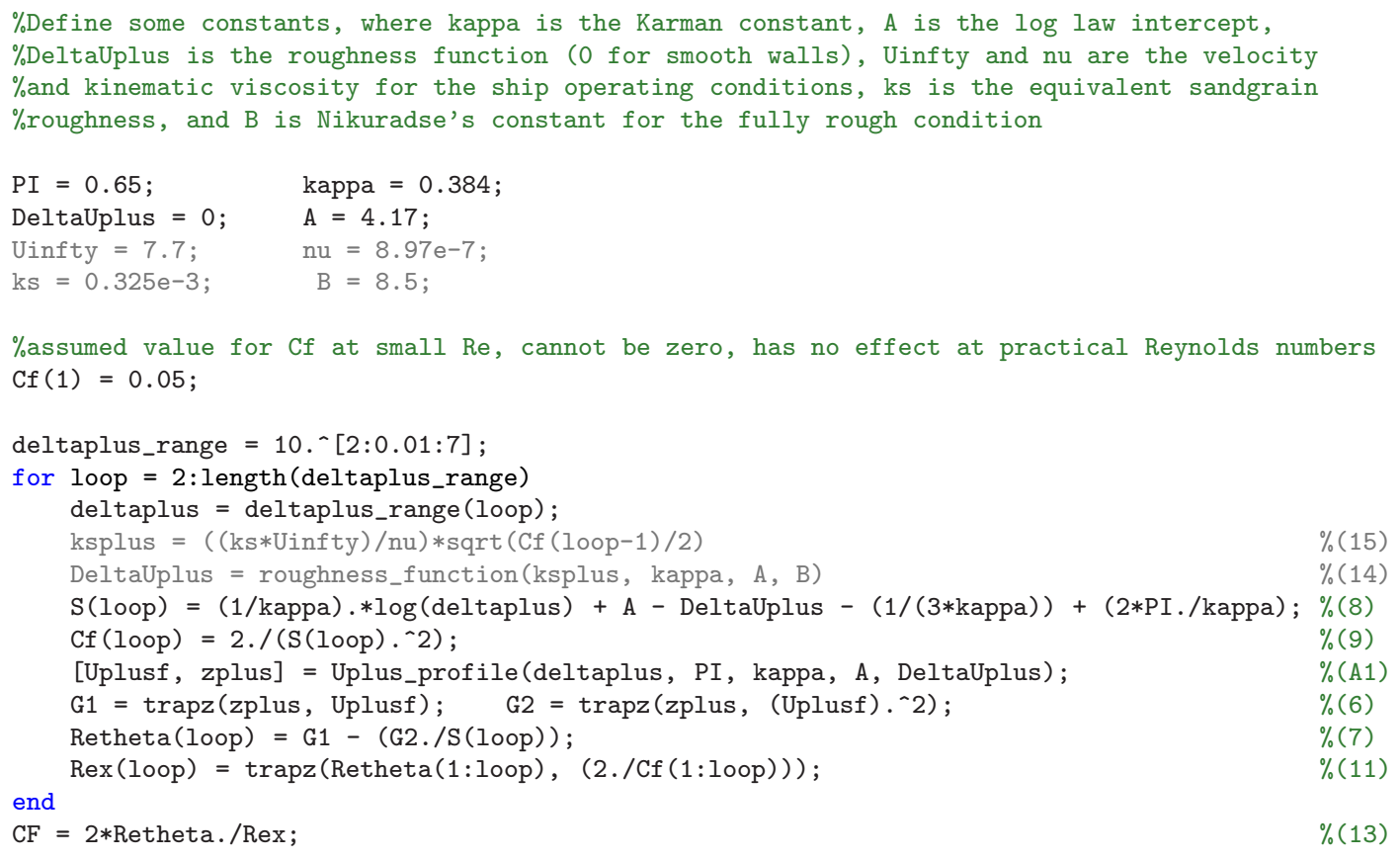

The mean velocity profile is calculated using the function Uplus_profile (below), which neglects the inner region profile assuming a logarithmic profile to the wall $\left(z_{1}^{+}=0.1\right.$, see figure 5$)$. We here use the wake profile suggested by Jones et al. Jones et al. [2001] which gives,

$$
U_{f}^{+}=\frac{1}{\kappa} \log z^{+}+A-\Delta U^{+}-\frac{z^{+^{3}}}{3 \kappa \delta^{+^{3}}}+\frac{2 \Pi z^{+^{2}}}{\kappa \delta^{+^{2}}}\left(3-\frac{2 z^{+}}{\delta^{+}}\right)
$$

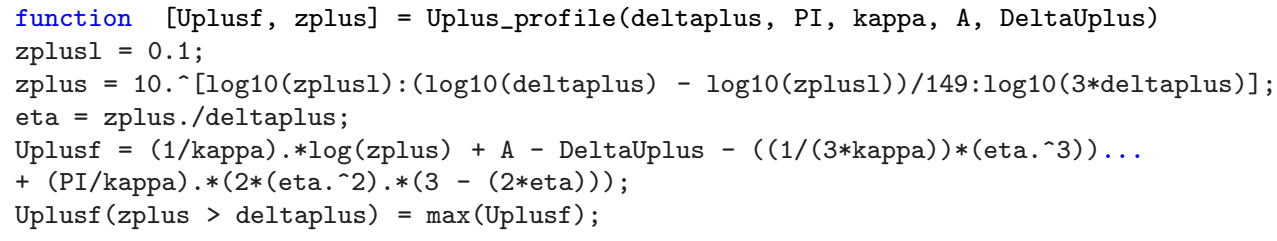




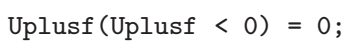

For the rough wall case, the additional function roughness_function (below) is used to calculate the roughness function $\Delta U^{+}$, given the variables $k_{s}^{+}$(and also the constants $\kappa, A$ and $B$ ). The calculated value for $\Delta U^{+}$is subsequently used in Uplus_profile to produce the mean velocity profile over the rough surface.

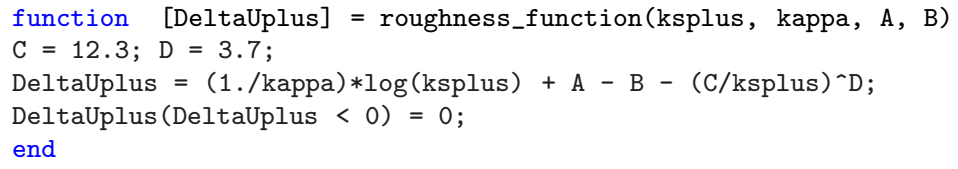

\section{References}

ABS 2013 Ship energy efficiency measures advisory. Tech. Rep.. American Bureau of Shipping.

Bendall, H. B. 2010 Cost of piracy: A comparative voyage approach. Maritime Economics 83 Logistics 12 (2), 178-195.

Busse, A., Lütuner, M. \& Sandham, N. D. 2015 Direct numerical simulation of turbulent flow over a rough surface based on a surface scan. Comput. Fluids 116, 129-147.

Busse, A., Tyson, C. J. \& Sandham, N. D. 2013 Direct numerical simulation of turbulent channel flow over engineering rough surfaces. In Proceedings of the eighth International Symposium on Turbulence and Shear Flow Phenomena. TSFP8, Poitiers, France.

Candries, M., Atlar, M., Mesbahi, E. \& Pazouki, K. 2003 The Measurement of the Drag Characteristics of Tin-free Self-polishing Co-polymers and Fouling Release Coatings Using a Rotor Apparatus. Biofouling 19, 27-36.

Chan, L., MacDonald, M., Chung, D., Hutchins, N. \& Ooi, A. 2015 A systematic investigation of roughness height and wavelength in turbulent pipe flow in the transitionally rough regime. J. Fluid Mech. 771, 743-777.

Choi, C. H., Scardino, A. J., Dylejko, P. G., Fletcher, L. E. \& Juniper, R. 2013 The effect of vibration frequency and amplitude on biofouling deterrence. Biofouling 29:2, 195-202.

Chung, D., Chan, L., MacDonald, M., Hutchins, N. \& Ooi, A. 2015 A fast direct numerical simulation method for characterising hydraulic roughness. J. Fluid Mech. 773, 418-431.

Colebrook, C. F. \& White, C. M. 1937 Experiments with fluid friction in roughened pipes. Philosophical Transactions of the Royal Society A: Mathematical, Physical and Engineering Sciences 161 (906), 367-381.

Coles, D. 1956 The law of the wake in the turbulent boundary layer. J. Fluid Mech. 1, 191-226. 
Driest, E. R. V. 1956 On turbulent flow near a wall. J. Aeronaut. Sci. 23, 1007-1011.

Flack, K. A. \& Schultz, M. P. 2010 Review of hydraulic roughness scales in the fully rough regime. J. Fluids Eng. 132, 041203.

Flack, K. A., Schultz, M. P. \& Connelly, J. S. 2007 Examination of a critical roughness height for outer layer similarity. Phys. Fluids 19, 095104.

Granville, P. S. 1958 The frictional resistance and turbulent boundary layer of rough plates. Tech. Rep. 1024. Navy Department.

Hutchins, N., Nickels, T. B., Marusic, I. \& Chong, M. S. 2009 Hot-wire spatial resolution issues in wall-bounded turbulence. J. Fluid Mech. 635, 103-136.

ITTC 2008 The resistance committee - final report and recommendations to the 25th ITTC. In Proc. 25th International Towing Tank Conference. Fukoaka.

ITTC 2011 Recommended procedures. fresh water and seawater properties. Tech. Rep.. ITTC, 26th ITTC Specialist Committee on Uncertainty Analysis.

Jones, M. B., Marusic, I. \& Perry, A. E. 2001 Evolution and structure of sink-flow turbulent boundary layers. J. Fluid Mech. 428, 1-27.

Krogstadt, P. \& Antonia, R. A. 1999 Surface roughness effects in turbulent boundary layers. Exp. Fluids 27, 450-460.

Kulandaivelu, V. 2012 Evolution of zero pressure gradient turbulent boundary layers from different initial conditions. PhD thesis, University of Melbourne, Australia.

Leer-Andersen, M. \& LARsson, L. 2003 An experimental/numerical approach for evaluating skin friction on full-scale ships with surface roughness. J. Mar. Sci. Technol. 8, 26-36.

Lewthwaite, J. C., Molland, A. F. \& Thomas, K. W. 1984 An investigation into the variation of ship skin frictional resistancce with fouling. Royal Institution of Naval Architects Transactions 127, 269-284.

Ligrani, P. M. \& Bradshaw, P. 1987 Spatial resolution and measurement of turbulence in the viscous sublayer using subminiature hot-wire probes. Exp. Fluids 5, 407-417.

Ligrani, P. M. \& Moffat, R. J. 1986 Structure of transitionally rough and fully rough turbulent boundary layers. J. Fluid Mech. 162, 69-98.

Min, K.-S. \& KANG, S.-H. 2012 Study on the form factor and full-scale ship resistance prediction method. J. Mar. Sci. Technol. 15, 108-118.

Monty, J. P., Allen, J. J., Lien, K. \& Chong, M. S. 2011 Modification of the large-scale features of high reynolds number wall turbulence by passive surface obtrusions. Exp. Fluids 51(6), $1755-1763$.

Moody, L. F. 1944 Friction facctors for pipe flow. Trans ASME 66, 671-684.

Nagib, H. M., Chauhan, K. A. \& Monkewitz, P. A. 2007 Approach to an asymptotic state for zero pressure gradient turbulent boundary layers. Phil. Trans. R. Soc. A 365, 647-664. 
NickeLS, T. 2010 IUTAM symposium on the physics of wall-bounded turbulent flows on rough walls. Springer.

NikURADSE, J. 1932 Gesetzmassigkeiten der turbulenten stromung in glatten rohren. Forsch. Auf Dem Gebiet des Ingenieurwesens 3, 1-36.

Nugroho, B., Hutchins, N. \& Monty, J. P. 2012 Large-scale spanwise periodicity in a turbulent boundary layer induced by highly ordered and directional surface roughness. Int. J. Heat Fluid Fl. 41, 90-102.

Prandtl, L. \& Schlichting, H. 1955 The resistance law for rough plates. Tech. Rep. 258. Navy Department, translated by P. Granville.

Psaraftis, H. N. \& Kontovas, C. A. $2009 \mathrm{CO}_{2}$ emission statistics for the world commercial fleet. WMU Journal of Maritime Affairs 8 (1), 1-25.

REICHARDT, H. 1951 Vollst andige darstellung der turbulenten geschwindigkeitsverteilung in glatten leitungen (complete representation of turbulent velocity distribution in smooth pipes). $Z$. Angew. Math. Mech. 31(7), 208-219.

Scardino, A. J., Fletcher, L. E. \& Lewis, J. A. 2009 Fouling control using air bubble curtains: protection for stationary vessels. J. Mar. Eng. Tech. 310, 310.

Schockling, M. A., Allen, J. J. \& Smits, A. J. 2006 Roughness effects in turbulent pipe flow. JFM 564, 267-285.

SchoenherR, K. E. 1932 Resistance of flat surfaces moving through a fluid. Trans. Soc. Nav. Archit. Mar. Eng. 40, 279-313.

Schultz, M. P. 2004 Frictional resistance of antifouling coating systems. J. Fluids Eng. 126, 1039.

Schultz, M. P. 2007 Effects of coating roughness and biofouling on ship resistance and powering. Biofouling 23, 331-341(11).

Schultz, M. P., Bendick, J. A., Holm, E. R. \& Hertel, W. M. 2011 Economic impact of biofouling on a naval surface ship. Biofouling 27, 87-98.

Schultz, M. P. \& Flack, K. A. 2005 Outer layer similarity in fully rough turbulent boundary layers. Exp. Fluids 38, 328-340.

Schultz, M. P. \& Flack, K. A. 2007 The rough-wall turbulent boundary layer from the hydraulically smooth to the fully rough regime. J. Fluid Mech. 580, 381-405.

Schultz, M. P. \& Myers, A. 2003 Comparison of three roughness function determination methods. Exp. Fluids 35, 372-379.

Schultz, M. P. \& Swain, G. W. 1999 The effect of biofilms on turbulent boundary layers. Trans ASME 121, 44-51.

Schultz, M. P. \& Swain, G. W. 2000 The influence of biofilms on skin friction drag. Biofouling 15, 129-139. 
Spalding, D. B. 1961 A single formula for the law of the wall. Trans. ASME C: J. Appl. Mech. 28, 455-458.

Thakkar, M., Busse, A. \& Sandham, N. D. 2015 Turbulent fluid flow over aerodynamically rough surfaces using direct numerical simulations. In Proceedings of the ERCOFTAC workshop on Direct and Large Eddy Simulation. DLES10, Cyprus.

Townsend, A. A. 1956 The Structure of Turbulent Shear Flow. Cambridge University Press.

Townsend, A. A. 1976 The Structure of Turbulent Shear Flow. Cambridge University Press.

Townsin, R. L. 2003 The ship hull fouling penalty. Biofouling 19, 9-15.

Walker, J., Sargison, J. \& Henderson, A. 2013 Turbulent boundary-layer structure of flows over freshwater biofilms. Exp. Fluids 54, 1-17.

Walker, J., Schultz, M., Flack, K. \& Steppes, C. 2014 Skin-friction drag measurements on ship hull coating systems. In 30th Symposium on Naval Hydrodynamics. Hobart, Tasmania, Australia, 2-7 November 2014.

Watson, M. G., Scardino, A. J., Zalizniak, L. \& Shimeta, J. 2014 Colonisation and succession of marine biofilm-dwelling ciliates in response to environmental variation. Aquat. Microb. Ecol. In Press.

Wu, Y. \& Christensen, K. T. 2007 Outer-layer similarity in the presence of a practical roughwall topography. Phys. Fluids 19 (8), 085108.

YuAn, J. \& Piomelli, U. 2014 Estimation and prediction of the roughness function on realistic surfaces. J. Turbulence 15:6, 350-365. 


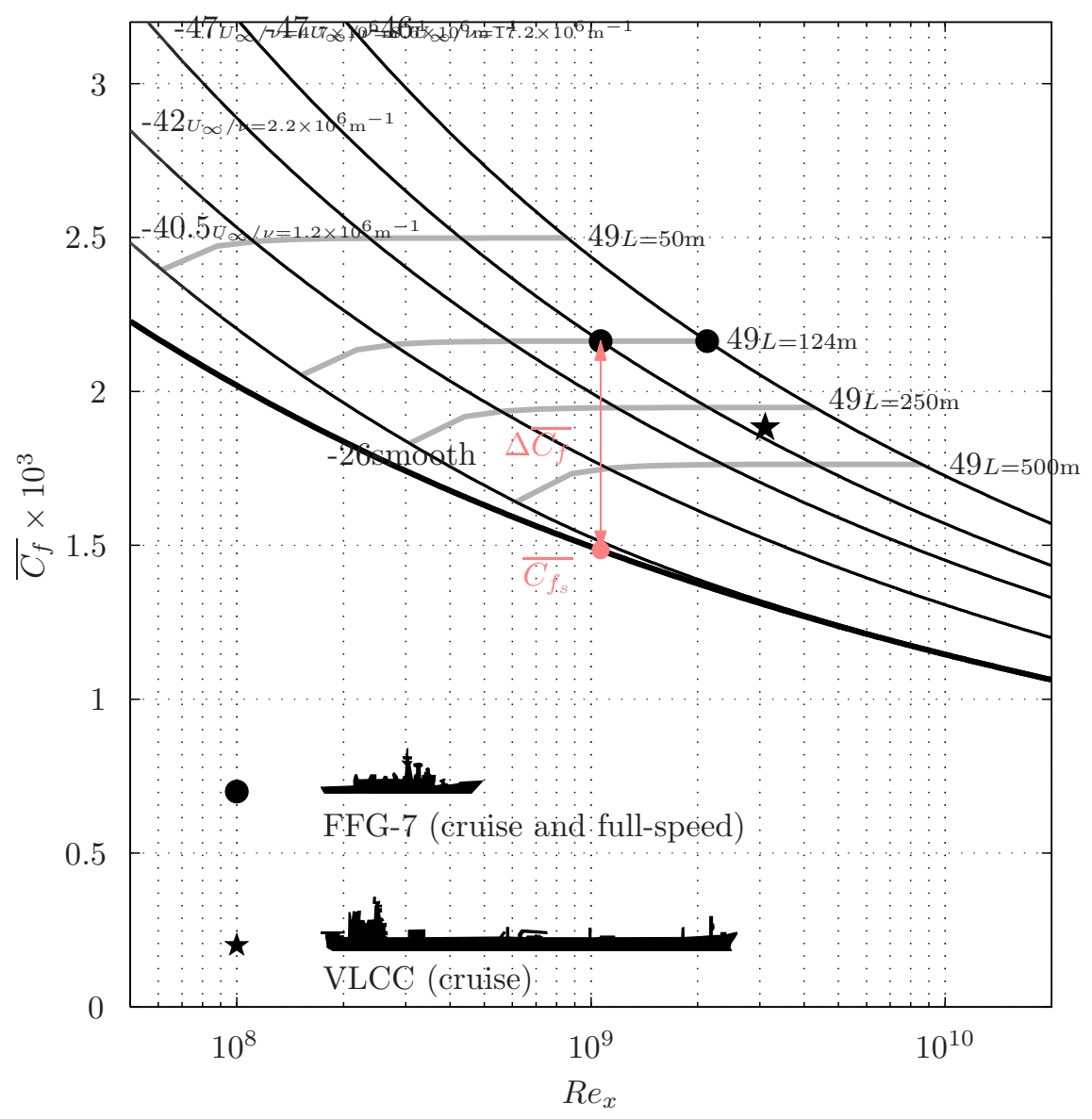

Figure 9: Average skin friction coefficient $\overline{C_{f}}$ against Reynolds number $R e_{x}$ for the (thick line) smooth surface and (thin lines) the tubeworm surface with $k_{s}=325 \mu \mathrm{m}$. Curves are shown for a range unit Reynolds numbers $\left(U_{\infty} / \nu\right)$. Gray curves show contours of constant length. Symbols show operating points for $(\bullet)$ a frigate (in cruise and at full-speed) and () a very large crude carrier. 